Al-Rafidain J Med Sci. 2022;2:21-25.

DOI: https://doi.org/10.54133/ajms.v2i.57

Research Article

\title{
Expression of NF-kB mRNA in Helicobacter pylori Positive Iraqi Patients with Inflammatory Bowel Diseases and Colorectal Cancer
}

\author{
Sinan Subhi Farhan (D) \\ Department of Anesthesia, College of Medical Science Techniques, The University of Mashreq, Baghdad, Iraq
}

Received: 2 Jan 2022; Revised: 1 Feb 2021; Accepted: 10 Feb 2022

\begin{abstract}
Background: Inflammatory bowel diseases (IBD) and colorectal cancer (CRC) are caused by a combination of variables, including environmental, host-related, and nutritional factors. Helicobacter pylori (H. pylori) is an environmental risk factor for many GIT disorders and is designated as a class I carcinogen. Aim: To investigate the prevalence of $H$. pylori in Iraqi patients diagnosed with IBD and CRC and the expression of NF- $\mathrm{kB}$ mRNA in those patients. Methods: Patients with GIT symptoms were tested for the existence of IBD and CRC in a cross-sectional observational study. In biopsies taken from GIT lesions, biochemical and histochemical approaches are employed to determine the presence of $H$. pylori and the expression of NF-кB mRNA. Results: $H$. pylori tests were positive in $33.3 \%$ of CRC patients, although this was not statistically significant compared to those who had negative testing. Only $63.3 \%$ of IBD patients had H. pylori infection. In the CRC group, 53.3\% of patients had negative NF-KB expression, whereas all of the patients in the IBD group had a negative test. Conclusion: Patients with CRC had a high prevalence of $H$. pylori, whereas IBD patients had a low frequency. Patients with CRC had high levels of NF- $\mathrm{KB}$ mRNA expression, whereas patients with IBS had none.
\end{abstract}

Keywords: Helicobacter pylori, NF-kB mRNA expression, colorectal cancer, inflammatory bowel disease

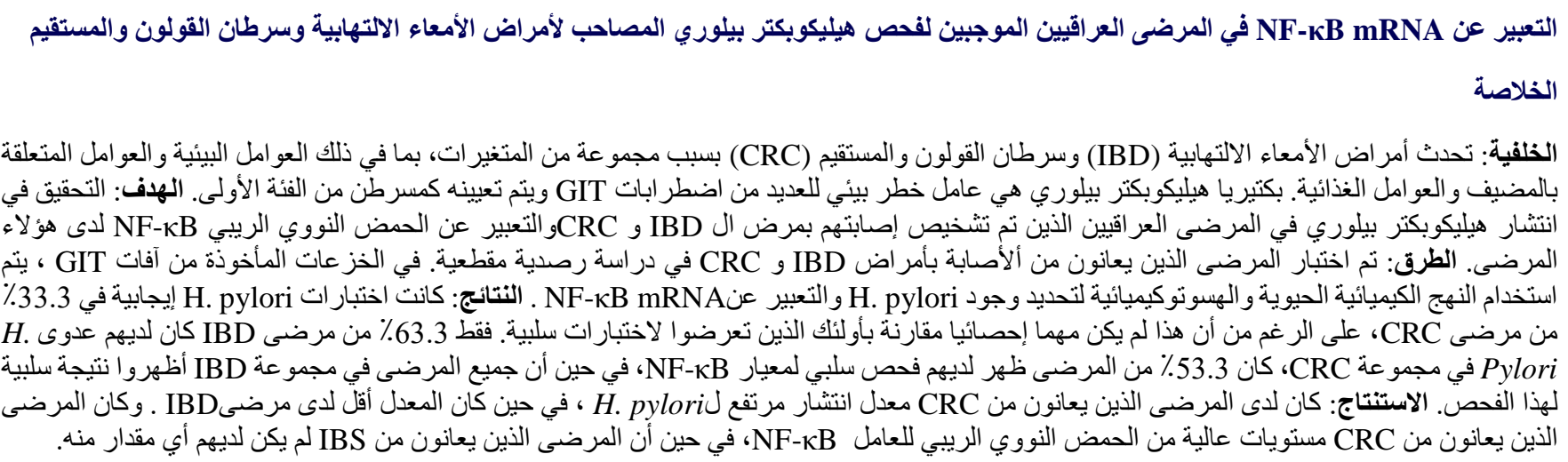

* Corresponding author: Sinan S. Farhan, College of Medical Science Techniques, The University of Mashreq, Baghdad, Iraq; E-mail: sinan.subhi@uom.edu.iq

Article citation: Farhan SS. Expression of NF- $\mathrm{BB}$ mRNA in Helicobacter pylori positive Iraqi patients with inflammatory bowel diseases and colorectal cancer. Al-Rafidain J Med Sci. 2022;2:21-25. doi: 10.54133/ajms.v2i.57.

(C) 2022 The Author(s). Published by Al-Rafidain University College. This is an open access article under the CC BY-NCND license. http://creativecommons.org/licenses/by/4.0/

Open Access

\section{INTRODUCTION}

Inflammatory bowel diseases (IBD) and colorectal cancer (CRC) are caused by a combination of variables, including environmental, host-related, and nutritional factors [1].
Helicobacter pylori (H. pylori), gram-negative bacteria, is a known environmental risk factor for many GIT disorders and is designated as a class I carcinogen by the World Health Organization [2]. This bacterium is expected to infect half of the world's population [3,4]. The cag 
Pathogenicity Island (cag-PAI) is a virulence determinant area found in $H$. pylori strains, and CagA (cytotoxinassociated gene) is one of many genes encoded by cag-PAI [5]. CagA is translocated from bacteria into human epithelial cells via a type IV secretion system and regulates certain signal transduction pathways to modulate cellular effects [6]. The "Correa's cascade," which involves progression from chronic gastritis to chronic atrophic gastritis, intestinal metaplasia, atypical hyperplasia, and eventually gastric cancer, is triggered by $H$. pylori [7]. Chronic $H$. pylori infection is linked to the activation of many pro-inflammatory signaling pathways [8]. Two of the most prominent pro-inflammatory pathways that are active during carcinogenesis are NF- $\kappa \mathrm{B}$ and STAT3 [9]. NF- $\kappa \mathrm{B}$ is a transcriptional factor that is activated by $H$. pylori infection and is constitutively activated in many GIT disorders including various cancers [10]. NF- $\kappa$ B activation causes the production of a number of pro-inflammatory cytokines and chemokines implicated in proliferation, angiogenesis, invasion, and apoptosis blocking [11]. Chronic inflammatory conditions are involved in the promotion of carcinogenesis by creating an inflammatory microenvironment [12]. NF- $\kappa \mathrm{B}$ is one of the most important inflammatory pathways in the development and progression of numerous malignancies, including gastric and colorectal tumors [13]. The transcriptional activities of $\mathrm{NF}-\kappa \mathrm{B}$ and STAT3 interact to optimize cytokine production and activation, according to a number of recent studies [14]. In the present study, we investigated the prevalence of $H$. pylori in Iraqi patients diagnosed with IBD and CRC and the expression of NF- $\kappa \mathrm{B}$ mRNA in those patients using biochemical and histological methods.

\section{METHODS}

Patients included 90 patients with normal colon (NC), 30 patients with IBD, and 30 patients with colorectal cancer (CRC) who attended the endoscopic unit at Baghdad Teaching Hospital. Biopsies were histopathologically examined to confirm the patients' diagnoses. For the double blind evaluation, two examiners looked at each patient's slide. The patients ranged in age from 15 to 62 years old. The patients were separated into three groups based on their ages: <20 years, 20-40 years, and > 40 years. For at least four weeks, no antibiotics, proton pump inhibitors (PPIs), or H2 blockers should be used by the individuals who have been chosen. They should also have stopped using bismuth-based therapy and NSAIDs for at least three weeks. The patients were put on a particular eating regimen and given laxatives the day before the colonoscopy to help them clear the colon. During colonoscopy, each patient's cecum, ascending, transverse, and descending colons (sigmoid) were sampled for intestinal biopsy. Two to four mucosal punch biopsy specimens were collected after endoscopic diagnosis. A biopsy urease test (BUT) was performed on one biopsy specimen to detect $H$. pylori in the tissue sample [15]. In Rapid Urease Medium, the urea reaction produced by $H$. pylori is faster than that produced by other urea-splitting organisms. As a result, the formation of a pink-red or red-violet hue is an efficient test for the diagnosis of $H$. pylori. Negative results were stored for up to 20 hours. For the creation of paraffin embedded tissue blocks, other biopsy tissues were preserved with $10 \%$ buffered neutral formalin. Sections of $5 \mu \mathrm{m}$ thickness were put on conventional slides for $\mathrm{H} \& \mathrm{E}$ staining and on charged slides for in situ hybridization using a biotinylated DNA probe and an in situ hybridization detection kit (Maxim Biotech/USA) to detect NF-кB mRNA [16].

\section{Statistical analysis}

Statistical analysis was done using software SPSS 16 for Windows. Differences among groups were evaluated by using Chi-square test and Fisher's exact test ( 2 x 2 Table). Differences were considered to be statistically significant at $\mathrm{P}$ value less than 0.05 .

\section{RESULTS}

Table 1 illustrates the incidence of IBD and CRC in the patients who were chosen based on their age. The highest prevalence of both illnesses were seen in those over the age of 40 ( $46.6 \%$ and $50 \%$, respectively), while the lowest rates were found in people under the age of 20 . (6.8\% for each group).

Table 1: Distribution of patients diagnosed with CRC disease and IBD according to age groups compared with those with normal colon (Total $n=240$ )

\begin{tabular}{cccc}
\hline Age ranges (year) & NC $(\%)$ & CRC (\%) & IBD (\%) \\
\hline$<20$ & $21(23.3)$ & $2(6.8)$ & $2(6.8)$ \\
$20-40$ & $23(25.6)$ & $14(46.6)$ & $13(43.2)$ \\
$>40$ & $46(51.1)$ & $14(46.6)$ & $15(50)$ \\
Total & $90(100)$ & $30(100)$ & $30(100)$ \\
\hline
\end{tabular}

The prevalence of $H$. pylori in the selected patients with GIT complaints is shown in Table 2. H. pylori was found in $66.7 \%$ of patients with normal colons, which is statistically significant when compared to patients who tested negative for $H$. pylori $(P<0.5)$. Meanwhile, $33.3 \%$ of CRC patients had a positive $H$. pylori test, which was not statistically significant when compared to those who had a negative test. Only $63.3 \%$ of IBD patients tested positive for $H$. pylori, which was shown to be non-significant when compared to those who tested negative. The majority of patients in the NC group $(58.33 \%)$ had low H. pylori density, whereas $25 \%$ had notable $H$. pylori density, according to the H\&E staining test of tissue sections. The majority of patients in the CRC group (44.5\%) had moderate $H$. pylori density, while $22.2 \%$ had significant density. 
Table 2: $H$. pylori prevalence among different age groups of patients diagnosed with CRT disease and IBD based on BUT results.

\begin{tabular}{lllllll}
\hline \multirow{2}{*}{$\begin{array}{c}\text { Age } \\
(\text { year })\end{array}$} & \multicolumn{2}{c}{$\mathrm{NC}(\mathrm{n}=90)$} & \multicolumn{2}{c}{$\mathrm{CRC}(\mathrm{n}=30)$} & \multicolumn{2}{l}{$\mathrm{IBD}(\mathrm{n}=30)$} \\
\cline { 2 - 7 } & $+\mathrm{ve}(\%)$ & $-\mathrm{ve}(\%)$ & $+\mathrm{ve}(\%)$ & $-\mathrm{ve}(\%)$ & $+\mathrm{ve}(\%)$ & $-\mathrm{ve}(\%)$ \\
\hline$<20$ & $6(28.6)$ & $15(71.4)$ & $1(50)$ & $1(50)$ & $1(50)$ & $1(50)$ \\
$20-40$ & $9(39.1)$ & $14(60.9)$ & $8(57.1)$ & $6(42.9)$ & $5(38.5)$ & $8(61.5)$ \\
$<40$ & $15(32.6)$ & $31(67.4)$ & $11(78.6)$ & $3(21.4)$ & $5(33.3)$ & $10(66.7)$ \\
Total & $30(33.3)$ & $60(66.7)$ & $20(66.7)$ & $10(33.3)$ & $11(36.7)$ & $19(63.3)$ \\
$P$ & \multicolumn{2}{c}{0.001} & \multicolumn{2}{c}{$>0.05$} & \multicolumn{2}{c}{$>0.05$} \\
\hline
\end{tabular}

In the IBD group, only $44 \%$ of patients had moderate $H$. pylori density and $11 \%$ had significant $H$. pylori density, indicating a similar pattern. Significant differences were not found in statistical analysis of the data (Table 3).

Table 3: H. pylori density in different groups based on H\&E staining method.

\begin{tabular}{lcccc}
\hline Patient group & Mild (\%) & Moderate (\%) & Marked (\%) & Total \\
\hline NC & $14(58.3)$ & $4(16.7)$ & $6(25)$ & 24 \\
CRC & $6(33.3)$ & $8(44.5)$ & $4(22.2)$ & $18^{\text {NS }}$ \\
IBD & $4(44.5)$ & $4(44.5)$ & $1(11)$ & $9^{\text {NS }}$ \\
Total & $36(38.7)$ & $35(37.6)$ & $22(23.7)$ & 93 \\
\hline
\end{tabular}

Table 4 shows that $75 \%$ of NC patients had negative NF$\kappa \mathrm{B}$ expression, which was not statistically significant when compared to those who had positive NF- $\kappa \mathrm{B}$ expression (25\%). However, $53.3 \%$ of patients in the CRC group had negative $\mathrm{NF}-\kappa \mathrm{B}$ expression, while all patients in the IBD group had negative NF- $\kappa \mathrm{B}$ expression testing. Figure 1 shows the different levels of $\mathrm{NF}-\kappa \mathrm{B}$ expression in tissue sections taken from the patients compared to sections with no expression.

Table 4: Expression of NF- $\mathrm{kB}$ mRNA in different age groups of patients with $\mathrm{CRC}$ and IBD based on in situ hybridization results.

\begin{tabular}{|c|c|c|c|c|c|c|}
\hline \multirow{2}{*}{$\begin{array}{c}\text { Age } \\
\text { (year) }\end{array}$} & \multicolumn{2}{|c|}{$\mathrm{NC}(\mathrm{n}=24)$} & \multicolumn{2}{|c|}{ CRC $(n=30)$} & \multicolumn{2}{|c|}{$\operatorname{IBD}(\mathrm{n}=30)$} \\
\hline & $+\mathrm{ve}(\%)$ & $-\mathrm{ve}(\%)$ & $+\mathrm{ve}(\%)$ & $-\operatorname{ve}(\%)$ & $+\mathrm{ve}(\%)$ & -ve $(\%)$ \\
\hline$<20$ & $2(40)$ & $3(60)$ & 0 & $2(6.7)$ & 0 & $2(6.7)$ \\
\hline $20-40$ & $3(42.9)$ & $4(57.1)$ & $8(57.2)$ & $6(42.8)$ & 0 & $13(43.3)$ \\
\hline$<40$ & $1(8.3)$ & 11(91.7) & $6(42.8)$ & $8(57.2)$ & 0 & $15(50)$ \\
\hline \multirow[t]{2}{*}{ Total } & $6(25)$ & $18(75)$ & 14(46.) & 16(53.) & 0 & $30(100)$ \\
\hline & \multicolumn{2}{|c|}{$P>0.05$} & \multicolumn{2}{|c|}{$P>0.05$} & \multicolumn{2}{|c|}{---- } \\
\hline
\end{tabular}

\section{DISCUSSION}

Infection with $H$. pylori may be the most common human infection and in many populations, and infection rates of $80-90 \%$ are not unusual [17]. The prevalence of $H$. pylori infection also varies widely by geographic area, age, race, and socioeconomic status; however, only few of those colonized people developed diseases related to $H$. pylori [18]. Regarding IBD, there are many evidences supporting a multifactorial genesis comprising a combination of genetic predisposition, immune response, and environment, most notably the bacterial gut microbes or luminal antigens [19]. Certain studies detected $H$. pylori infection among IBD patients, so they suggested a possible role of $H$. pylori in IBD group, although other studies suggested no possible role of $H$. pylori in IBD indicating that the role of $H$. pylori in IBD is still controversial [20]. The present study disclosed presence of $H$. pylori in $66.7 \%$ of CRC patients and $36.7 \%$ of IBD patients compared to $33.3 \%$ in the NC group, and analysis of data reflects nonsignificant differences. A recent meta-analysis study demonstrates that colorectal adenoma, advanced adenoma, and cancer were all associated with $H$. pylori infection [21], a result that support our primary finding in this regard. The role of inflammation and $H$. pylori-mediated activation of $\mathrm{NF}-\kappa \mathrm{B}$ in transcriptional regulation in cancer was recently clarified [22].

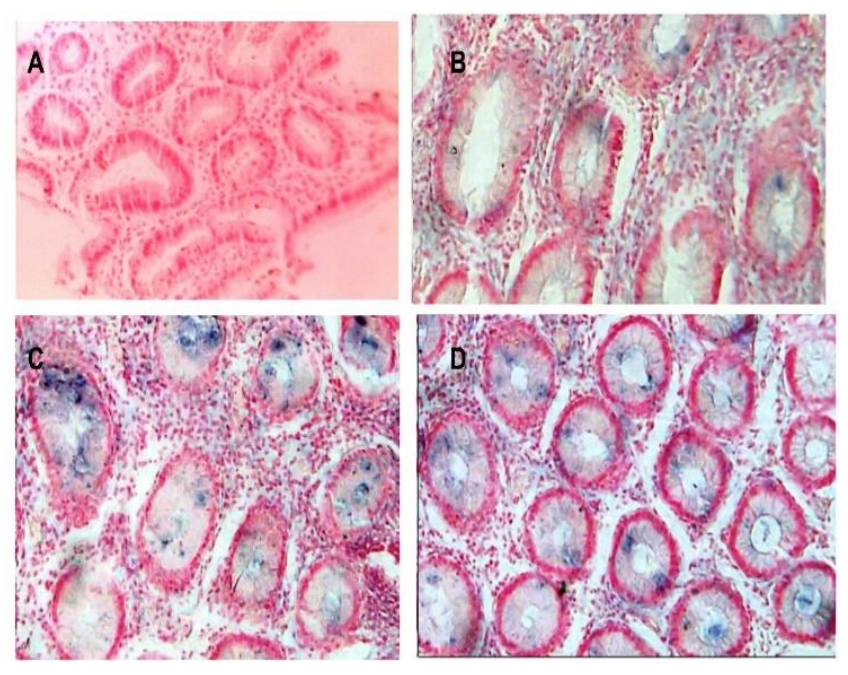

Figure 1: Expression of NF-kB mRNA. A: negative expression, B: Mild expression, C: moderate expression; D: Marked expression [BCIP/NBT stain (dark-blue) by In Situ hybridization staining counterstained with NFR].

The present study highlighted the influence of $H$. pyloriinduced NF- $\kappa \mathrm{B}$ mRNA expression of high rate in $\mathrm{CRC}$ patients, while none of the IBD patients demonstrates positive results. However, NF- $\kappa \mathrm{B}$ is involved as an important inflammatory signaling pathway in the pathogenesis of IBD [23]. Early studies have reported that constitutive NF- $\kappa$ B activation was found in the inflamed intestinal tissues of IBD patients [24], which was in conflicts with the reported outcomes in the present study. Previous studies also suggest that apoptosis and DNA damage are increased in GIT cells during infection with $H$. pylori [25]. Chronic $H$. pylori infection results in generation of a subpopulation of epithelial cells with high levels of DNA damage that are resistant to apoptosis [26]. The accumulation and survival of cells with damaged DNA heightens the risk of development of GIT cancers [27]. Moreover, the effectiveness of GIT epithelium cytoprotection has been found closely related to the virulence of $H$. pylori strains, particularly CagA subtypes 
[28]. The reason for the inconsistent findings reported to date is unclear, but it might be at least partly explained by the methodological issue. These include selection bias, small sample sizes and an inadequate consideration of potential confounding variables in the data analysis. One of the limitations of the present study is the small sample size which do not enable achieving significant differences in the obtained outcomes.

\section{Conclusion}

A relatively high $H$. pylori prevalence was detected only at the site of lesion of patients with colorectal cancers, and low prevalence in IBD patients. Patients with CRC showed high levels of NF- $\mathrm{KB}$ mRNA expression, while completely missed in IBS group.

\section{Acknowledgement}

The author thanks University of Baghdad for supporting the project.

\section{Conflict of interests}

The author declared no conflicting interests.

\section{Data sharing statement}

The datasets analyzed during the current study will be available from the corresponding author on a reasonable request.

\section{REFERENCES}

1. Cover TL, Peek RM. Diet, microbial virulence, and Helicobacter pylori-induced gastric cancer. Gut Microbes. 2013;4(6):482-493. doi: 10.4161/gmic.26262.

2. Ji HG, Piao JY, Kim SJ, Kim DH, Lee HN, Na HK, et al. Docosahexaenoic acid inhibits Helicobacter pylori-induced STAT3 phosphorylation through activation of PPARgamma. Mol Nutr Food Res. 2016;60(6):1448-1457. doi: 10.1002/mnfr.201600009.

3. Cover TL, Blaser MJ. Helicobacter pylori in health and disease. Gastroenterology. 2009;136(6):1863-1873. doi: 10.1053/j.gastro.2009.01.073.

4. Atherton JC, Blaser MJ. Coadaptation of Helicobacter pylori and humans: ancient history, modern implications. $J$ Clin Invest. 2009;119(9):2475-2487. doi: 10.1172/JCI38605.

5. Oliveira MJ, Costa AM, Costa AC, Ferreira RM, Sampaio P, Machado JC, et al. CagA associates with c-Met, E-cadherin, and p120-catenin in a multiproteic complex that suppresses Helicobacter pylori-induced cell-invasive phenotype. J Infect Dis. 2009;200(5):745-755. doi: $10.1086 / 604727$.

6. Hatakeyama M. Structure and function of Helicobacter pylori CagA, the first-identified bacterial protein involved in human cancer. Proc Jpn Acad Ser B Phys Biol Sci. 2017;93(4):196-219. doi: 10.2183/pjab.93.013.
7. Moss SF. The clinical evidence linking Helicobacter pylori to gastric cancer. Cell Mol Gastroenterol Hepatol. 2017;3(2):183-191. doi: 10.1016/j.jcmgh.2016.12.001.

8. Zhang XY, Zhang PY, Aboul-Soud MA. From inflammation to gastric cancer: role of Helicobacter pylori. Oncol Lett. 2017;13(2):543-548. doi: 10.3892/ol.2016.5506.

9. Grivennikov SI, Greten FR, Karin M. Immunity, inflammation, and cancer. Cell. 2010;140(6):883-899. doi: 10.1016/j.cell.2010.01.025.

10. Lee BL, Lee HS, Jung J, Cho SJ, Chung HY, Kim WH, et al. Nuclear factor-kappaB activation correlates with better prognosis and Akt activation in human gastric cancer. Clin Cancer Res. 2005;11(7):25182525. doi: 10.1158/1078-0432.CCR-04-1282.

11. Xia L, Tan S, Zhou Y, Lin J, Wang H, Oyang L, et al. Role of the NFkappaB-signaling pathway in cancer. Onco Targets Ther. 2018;11:2063-2073. doi: 10.2147/OTT.S161109.

12. Qu X, Tang Y, Hua S. Immunological approaches towards cancer and inflammation: a cross talk. Front Immunol. 2018;9:563. doi: 10.3389/fimmu.2018.00563.

13. Yoon J, Cho SJ, Ko YS, Park J, Shin DH, et al. A synergistic interaction between transcription factors nuclear factor-kappaB and signal transducers and activators of transcription 3 promotes gastric cancer cell migration and invasion. BMC Gastroenterol. 2013;13:29. doi: 10.1186/1471-230X-13-29.

14. Liu FT, Jia L, Wang P, Wang H, Farren TW, Agrawal SG. STAT3 and NF-kappaB cooperatively control in vitro spontaneous apoptosis and poor chemo-responsiveness in patients with chronic lymphocytic leukemia. Oncotarget. 2016;7(22):32031-32045. doi 10.18632/oncotarget.8672.

15. Stingl K, Altendorf K, Bakker EP. Acid survival of Helicobacter pylori: how does urease activity trigger cytoplasmic $\mathrm{pH}$ homeostasis. Trends Microbiol. 2002;10(2):70-74. doi: 10.1016/S0966842X(01)02287-9. doi: 10.1016/s0966-842x(01)02287-9.

16. Veselinyová D, Mašlanková J, Kalinová K, Mičková H, Mareková M, Rabajdová M. Selected in situ hybridization methods: Principles and

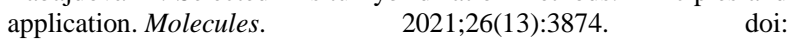
10.3390/molecules26133874.

17. Bravo D, Hoare A, Soto C, Valenzuela MA, Quest AF. Helicobacter pylori in human health and disease: Mechanisms for local gastric and systemic effects. World J Gastroenterol. 2018;24(28):3071-3089. doi: 10.3748/wjg.v24.i28.3071.

18. Lu C, Yu Y, Li L, Yu C, Xu P. Systematic review of the relationship of Helicobacter pylori infection with geographical latitude, average annual temperature and average daily sunshine. BMC Gastroenterol. 2018;18(1):50. doi: 10.1186/s12876-018-0779-x.

19. Lee YJ, Park KS. Irritable bowel syndrome: emerging paradigm in pathophysiology. World J Gastroenterol. 2014;20(10):2456-2469. doi: 10.3748/wjg.v20.i10.2456

20. Li C, Shuai Y, Zhou X, Chen H. Association between Helicobacter pylori infection and irritable bowel syndrome: A systematic review and meta-analysis. Medicine (Baltimore). 2020;99(50):e22975. doi: 10.1097/MD.0000000000022975.

21. Choi DS, Seo SI, Shin WG, Park CH. Risk for colorectal neoplasia in patients with Helicobacter pylori infection: A systematic review and meta-analysis. Clin Transl Gastroenterol. 2020;11(2):e00127. doi: $10.14309 / \mathrm{ctg} .0000000000000127$.

22. Zhu S, Soutto M, Chen Z, Peng D, Romero-Gallo J, Krishna US, et al. Helicobacter pylori-induced cell death is counteracted by NF- $\mathrm{\kappa B}$ - 
mediated transcription of DARPP-32. Gut. 2017;66(5):761-762. doi: 10.1136/gutjnl-2016-312141.

23. Liu T, Zhang L, Joo D, Sun SC. NF- $\kappa B$ signaling in inflammation. Signal Transduct Target Ther. 2017;2:17023. doi: 10.1038/sigtrans.2017.23.

24. Rogler G, Brand K, Vogl D, Page S, Hofmeister R, Andus T, et al. Nuclear factor kappaB is activated in macrophages and epithelial cells of inflamed intestinal mucosa. Gastroenterology. 1998;115(2):357369. doi: 10.1016/s0016-5085(98)70202-1.

25. Miyata H, Yamasaki M, Kurokawa Y, Takiguchi S, Nakajima K, Fujiwara Y, et al. Survival factors in patients with recurrence after curative resection of esophageal squamous cell carcinomas. Ann Surg Oncol. 2011;18(12):3353-3361. doi: 10.1245/s10434-011-1747-7.
26. Chaturvedi R, Asim M, Romero-Gallo J, Barry DP, Hoge S, de Sablet $\mathrm{T}$, et al. Spermine oxidase mediates the gastric cancer risk associated with Helicobacter pylori CagA. Gastroenterology. 2011;141(5):16961708. doi: 10.1053/j.gastro.2011.07.045.

27. Chon I, Choi C, Shin CM, Park YS, Kim N, Lee DH. Effect of Helicobacter pylori eradication on subsequent dysplasia development after endoscopic resection of gastric dysplasia. Korean $J$ Gastroenterol. 2013;61(6):307-312. doi: 10.4166/kjg.2013.61.6.307.

28. Toh JWT, Wilson RB. Pathways of gastric carcinogenesis, Helicobacter pylori virulence and interactions with antioxidant systems, vitamin $\mathrm{C}$ and phytochemicals. Int J Mol Sci. 2020;21(17):6451. doi: 10.3390/ijms2117641. 